\title{
WILEY
}

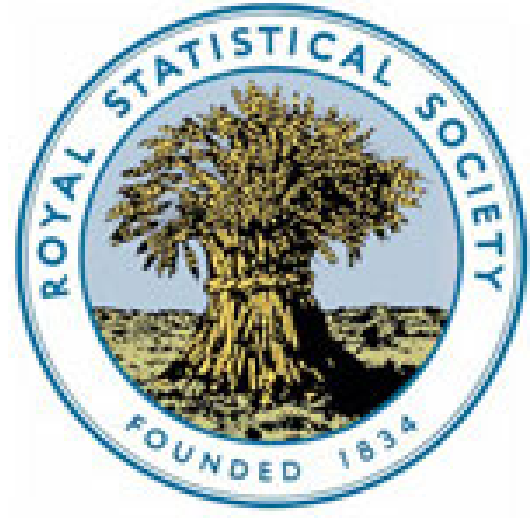

Human Capital and the Cost of the War

Author(s): Harold Boag

Source: Journal of the Royal Statistical Society, Vol. 79, No. 1 (Jan., 1916), pp. 7-17

Published by: Wiley for the Royal Statistical Society

Stable URL: http://www.jstor.org/stable/2340631

Accessed: 10/06/2014 21:19

Your use of the JSTOR archive indicates your acceptance of the Terms \& Conditions of Use, available at http://www.jstor.org/page/info/about/policies/terms.jsp

JSTOR is a not-for-profit service that helps scholars, researchers, and students discover, use, and build upon a wide range of content in a trusted digital archive. We use information technology and tools to increase productivity and facilitate new forms of scholarship. For more information about JSTOR, please contact support@ jstor.org.

Wiley and Royal Statistical Society are collaborating with JSTOR to digitize, preserve and extend access to Journal of the Royal Statistical Society. 


\section{Human Capital and the Cost of the War.}

By Harold Boag, A.I.A.

The great loss of life which is taking place in the present war has brought into prominence the question, often debated by political economists, of the valuation as a form of capital of the skill and knowledge embodied in the workers of a country. There is a tragic irony in the fact that it is chiefly when we are suffering from the effects of the loss of life that we desire most to determine its value. The phrase "the loss in men and material" has recently become a commonplace: the determination of the economic value of man in analogous terms to that in which we value material is, however, found to be as difficult a problem as ever.

Owing to the operations of the war being upon a scale unprecedented in history, and owing to it being difficult to form even an approximate estimate of its duration, any attempts to calculate the total cost of the war must at the present time be doomed to failure. While this is so, the estimates which have been made may serve a useful purpose, inasmuch as they give rise to discussion as to methods of ascertainment, which may be a help towards greater accuracy, when, at the conclusion of the war, the various elements of cost can be more correctly determined.

With this object in view, viz., the discussion of methods rather than the calculation of numerical values, it is interesting for us to endeavour to answer the following questions: (1) Is it correct to include in any estimate of the cost of a war the diminution of capital due to the loss of human life ? and (2) If so, on what basis should such capital value be calculated?

The answer to the first question depends very largely upon the primary consideration as to whether it is right to include in any estimates of wealth the value of the capabilities of the persons who enjoy such wealth.

Before quoting the opinion of economists on this question, it will perhaps tend to give a certain definiteness to our ideas if we consider, by means of a simple illustration, the analogy between material and personal capital.

Let us take as an example of the former the plant and machinery of a manufacturing company, and as an example of the latter an average workman. The erection of the plant and machinery necessitates an expenditure of labour and material. In some cases the period of erection is necessarily lengthy, and as no 
production is obtained during this period, interest on capital forms part of the total cost of the plant. When erected, there may be an experimental period, during which further expenditure is incurred, and an inadequate return obtained in the form of production. When the plant is in complete working condition, the full production is obtained, against which there has to be set the cost of running, the cost of repairs and renewals, a charge for depreciation, or a sinking fund reserve to provide new machinery on the wearing out or obsolescence of the existing plant. The excess of the value of the production over these charges forms the net yield, which may include both interest on capital and profit.

The case of the average workman has many points in common. During his childhood and up to, say, 15 years of age, expenditure is incurred on his food, clothing and education. Between the ages of, say, 15 and 21 there is an apprenticeship or experimental period, during which the expense continues, but a small return is obtained in the form of wages. From the age of 21 to, say, 60 or 65 , the man earns full wages, but, out of such wages, has to provide for his present maintenance, his cost of repairs, together with a provision for old age, by means of his National Insurance and Friendly Society payments. He has also to pay for the maintenance of his children, which is practically a sinking fund charge to provide the workers for the next generation. Any excess of wages over the cost of necessities is the reward of his industry, or the profit on his human capital.

Seeing that the analogy is so close, are we justified in concluding that every human being has a capital value, in the same manner in which a capital value is assigned to a piece of machinery?

Professor Nicholson, in his Principles of Political Economy, has said, "One of the earliest, and also one of the most enduring "forms of capital was living capital-meaning thereby not only " oxen and sheep, but men, women and children. The animal "first tamed by man was man." And Ruskin, in his essay, " Ad Valorem," has said, "There is no wealth but life. Life, " including all its powers of love, of joy and of admiration." While this may be true, it is impossible to give comparative values to love or admiration. We may be able to compensate a widow for the material losses directly consequent upon her husband's death, but the losses of "love, joy and admiration" are beyond the computation of the most skilful mathematician. It is this loss-the loss of men, not merely as producers, but of men as sons, brothers and husbands-that forms the unascertainable, but the most awful, cost of the present war. 
But because part of our loss is incalculable that is no reason why we should not endeavour to arrive at as true an estimate as is possible of that portion of the cost which can be expressed in terms of material wealth. In this we are supported by many political economists. Adam Smith included as one of his four forms of fixed capital "the acquired and useful abilities" of the members of a society. "The acquisition of such talents, by the " maintenance of the acquirer during his education, study or " apprenticeship, always costs a real expense, which is a capital " fixed and realised, as it were in his person. Those talents, as " they make a part of his fortune, so do they likewise of the society "to which he belongs." John Stuart Mill, in a footnote to his chapter on "Unproductive Labour," said, "The human being " himself I do not class as wealth. $\mathrm{He}$ is the purpose for which "wealth exists. But his acquired capacities, which exist only " as means and have been called into existence by labour, fall " rightly, as it seems to me, within that designation."

If, therefore, for the particular purpose we have in view, we restrict our ideas of wealth from the philosophical definition of Ruskin to the narrower, but more calculable, limits laid down by Mill, we are able to say, in answer to our first question, that there is as much reason for the inclusion in the cost of the war of the loss of human capital sustained by the nation as there is for the loss of material capital. They are both the result of past production which has been consumed, and have, therefore, both cost a real expense, and in each case further production is diminished by their destruction.

There are one or two important points, however, which should be remembered in connection with the valuation of the capital fixed and embodied in human beings :-

(1) The method by which any values of human capital are obtained and exactly what such values represent should be clearly borne in mind when they are used in later calculations. Different methods of arriving at values may be particularly suited to various problems. For example, one method may more correctly ascertain the loss of capital due to emigration, another to war losses, and a third be more suitable for use in connection with the problem of the distribution of wealth.

(2) Care must be taken to see that the same item of cost is not duplicated by being valued, perhaps in a somewhat different guise, under the headings of both material and personal capital.

(3) The interdependence of the values of material and personal capital must also be borne in mind. Just as the large destruction 
of any particular form of material capital may affect the value of the remaining kind of that capital, so any large (and particularly any sudden) depletion of the ranks of the labourers may not only cause direct loss through diminished production, but may also reduce the value of the material capital which is "thrown out of "employment" by the lack of labour.

(4) We must, above all, beware of "arguing in a circle," particularly in connection with such subjects as the present, when the steps of the argument are frequently obscured by a mass of complicated figures. It is, for example, bad reasoning to arrive at a value of human capital largely by capitalising actual incomes at some assumed rate of interest, and later to endeavour to show by a comparison of such values with values of material capital employed, that labour should receive a certain proportionate return in the form of wages.

The above considerations may appear somewhat obvious; but, as will be shown later, it is owing to the neglect of some of these precautions that errors have been made by one or two recent writers on the subject.

We now come to our second question. On what basis should the value of human life, from an economic point of view, be calculated?

In studying the answers given to this question by economists, we are at first amazed by the extreme divergence of the results obtained. On closer examination, however, it will be found that the results are in reality often answers to very different questions.

The methods adopted in arriving at these results may be conveniently divided into two groups : those based on past cost and those based on future yield. In this respect the methods of valuing human capital are analogous to those adopted by actuaries in the valuation of life policies, and termed by them the retrospective and prospective methods. By the former, life policies are valued by accumulating at interest the past premiums paid, and subtracting the accumulated value of past claims; by the latter, the discounted value of the benefit assured is calculated, less the discounted value of the premiums to be paid. In the case of a life policy, however, when the same rate of interest is used, the two methods produce identical results; but in valuing human capital the results differ considerably, because the gross return in the form of wages calculated on the cost is generally greater than the rates of interest usually assumed in capitalising income.

The "cost," or what we may term the retrospective method of valuing human capital, has a disadvantage owing to the fact 
that it is impossible to determine how nuch of the cost of education, maintenance, etc., is strictly necessary to produce an incomeearner, as distinct from those capacities for "love, joy and "admiration," which may not be incidental to the production of material wealth.

On the other hand, by the "yield," or prospective method, the capital has a different value to $(a)$ the man himself $(b)$ his family, and $(c)$ his employer, according as we capitalise $(a)$ his gross income (b) his gross income less his personal cost of maintenance $(c)$ the gain on his labour to his employer, on the assumption that such labour cannot be replaced. Again, the value of the man to the nation may be taken as: $(a)$ the value of his gross income; or $(b)$ the value of his net income; or as the sum of the values $(a)$ and $(c)$, i.e., the capitalised value of his full earning power both to himself and his employer ; or $(b)$ and $(c)$, the value of such earning power, less his cost of maintenance.

Bearing these points in mind, it is interesting for us to briefly review some of the methods which have been suggested for the valuation of human capital.

Towards the end of the seventeenth century, Sir William Petty wrote his essays on "Political Arithmetic," and in one of his many interesting digressions set down "the way of computing the value "of every head one with another of the people of England." $\mathrm{He}$ estimated the "expense per head" of the population to be $7 l$., or $42,000,00 o l$. in all, and subtracting therefrom $8,000,000 l$. as the yearly rent of lands and $8,000,00 o l$. as the yearly profit of all personal estate, he assumed the balance of $26,000,000 l$. to be derived from the labour of the people. He then assumed that the mass of mankind was, similarly to land, worth twenty years' purchase, and thus arrived at a total of 520,00o,oool. as the capitalised value of the whole people, or an average value, taking men, women and children together, of, say, 8ol. per head, "from whence," he said, "we may learn to compute the loss we have sustained by the plague, "by the slaughter of men in war, and by the sending of them "abroad into the services of foreign princes."

In Sir Robert Giffen's paper on "The Cost of the Franco"German War of 1870-71" a rough method of estimating the value of the loss of human life and of the loss due to the invaliding of the sick and wounded is given. Sir Robert Giffen followed Petty in adopting the yield method, but instead of capitalising at twenty years' purchase, he took the present value of an annuity at age 25 as being worth, say, $15 l$., and multiplying this by an average annual earning power of $40 l$., arrived at a value of $600 l$. 
per person, which he then multiplied by the number of casualties, having first adjusted such number to allow for those whose value was impaired but was not entirely destroyed. He emphasised very strongly, however, the fact that the calculation was only given as an imperfect estimate in order to convey to the mind some idea of the nature of the loss sustained, and he did not include the figure obtained in his final cost, stating that it was a loss "on " which no pecuniary value could properly be placed."

One of Giffen's qualifications is very important as bearing upon certain recent estimates. After giving his calculation for the value of the loss of human capital, he said, "It should be " remembered, besides, that part of the losses on this account"so far at least as they affect the surviving community-must " have been reckoned under the previous head" (i.e., the losses of material capital). "In any general sum of the expenses of the " war, it would be improper to include both items to the full " amount if they could be exactly ascertained." Although Giffen in writing had in view the licence tax, his remark has a general application and is important whenever we are including losses both of personal and material capital. For example, in Mr. Edgar Crammond's paper on "The Cost of the War," read before the Royal Statistical Society in March last, an estimate of the cost of pensions to widows of soldiers payable during the currency of the war is included, in addition to a capital value for the human life destroyed. Is this not a duplication of cost, to which Sir Robert Giffen's warning would apply? If the total cost to the nation of the loss of human capital is charged first, then a pension to the widow, presumably for the loss of future income of her husband, is merely a redistribution (by way of taxation) of the national income, the widow's total monetary loss (for which she is receiving partial compensation) having been included as part of the national loss under the head of human capital.

Dr. Farr's writings on "The Economic Value of Man" are particularly interesting. In a paper given before the Statistical Society (Vol. xvi, pp. 38-44) on the equitable taxation of property, he said: "The characteristic of life property in wages . . . is " that it is inherent in man, and is the value of his services-of " the direct product of his skill and industry. In slaves it is "vendible and transferable; in freemen it is unalienable; but " it is not the less on that account property. . . . The present "value of the person's probable future earnings, minus the necessary " outgo in realising those earnings, is the present value of that 
"person's services." In order to determine such value, Dr. Farr applied the science of life contingencies to the problem. After fixing certain amounts of income as receivable and certain outgo as necessary during each year of age, and assuming rates of mortality and interest, he arrived at a value at birth and at every subsequent age of (1) the future wages and (2) the future cost of maintenance, and by taking the difference between these values he obtained the present value at each age of the future profit. The examples given to illustrate the above method were based upon statistics collected as to the wages of agricultural labourers, but some years later Dr. Farr, in the 39th Annual Report of the Registrar-General, applied the method to the whole population. "The capitalisation of personal incomes," he stated, "always "proceeds upon the determination of the present value at any "age of the future annual earnings at that and all future ages"hence the value of future wages rises from the date of birth, "when it is a notable quantity; is highest in the labouring class "at the age of 25 , and declines as age advances, until in extreme " old age, when no wages are earned, it disappears. . . . Taking "a series of observations on the wages of agricultural labourers "some years ago at different ages; determining their value by "a life table at 5 per cent. rate of interest for each age; and " multiplying the numbers living by these values, it is found that "the mean gross value at all ages is $349 l$. But the mean value " of the subsistence of the labourer as child and man, determined "by the same method, is $199 l$; and, deducting this sum from " $349 l$., there remains ${ }^{5} 50 l$. as the mean net value of the male "population estimated by this standard of the agricultural "labourer. To extend this value to the whole population "(including females), the standard might be lowered from I5ol. " to r rol. per head." After giving calculations for the capitalisation of other forms of income arising from personal exertions, he arrived at the following conclusion: "The minimum value of the popula" tion of the United Kingdom, men, women and children, is $\mathrm{I}_{59 l}$. "per head, that is, the value inherent in them as a productive, "money-earning race. The incomes chiefly under Schedules D, "B and $\mathrm{E}$ raise the mean value from $\mathrm{x}$ iol. to $\mathrm{s}$ ol."

Here it is seen that Dr. Farr would have obtained a value of over 3 ool. if he had taken the capitalised value of the gross income, but his figure was reduced to 5 ol. by only capitalising the "profit" resulting from the man's labour. This method of taking the value of the man's wages, less his cost of maintenance, gives a useful figure for some purposes. For example, it arrives at the economic 
value of the man to his family. If the wage-earner be removed his family is impoverished by the amount of his income, less his own cost of maintenance. But in calculations of national loss, the loss of income is usually compared with the total national income and not with the national savings, and, therefore, it is often better to arrive at a capitalised value of the diminution of gross income instead of the "surplus" income.

Professor Marshall, in his Principles of Economics, after discussing the two methods of discounting future production and of accumulating past consumption, has said : "Many writers assume, " implicitly at least, that the net production of an average individual " and the consumption during the whole of his life are equal, or " in other words, that he would neither add to nor take from the " material well-being of a country in which he stayed all his life. " On this assumption, the above two plans of estimating his value " would be convertible; and then, of course, we should make " our calculations by the latter and easier method. We may, "for instance, guess that the total amount spent on bringing up " an average child of the lower half of the labouring classes, say, " two-fifths of the population, is rool.; for the next fifth, we may " put the sum at ${ }^{2} 75 l$.; for the next fifth, 3ool.; for the next " tenth at 5ool.; and the remaining tenth at $\mathrm{x}, 200 l$., or an average " of $300 l$. But, of course, some of the population are very young " and have had little spent on them; others have nearly got to " their life's end : and, therefore, on these assumptions the average "value of an individual is perhaps 20ol."

Professor J. S. Nicholson, in an article contributed to the Economic Journal in 1891, endeavoured to form an estimate of "The Living Capital of the United Kingdom" by proceeding somewhat on the lines adopted by Sir Robert Giffen in arriving at estimates of the national material capital. Giffen capitalised those portions of the national income which are supposed to be derived from material capital and added estimated amounts for the material capital which produced no income. Similarly, Professor Nicholson capitalised the remaining portion of the national income which he assumed to be derived from living capital. By capitalising the wages of the labouring classes at thirty years' purchase he obtained a figure of $24,000,000,000 l$. To this he added the capitalised value, at thirty years' purchase, of a portion of the income coming under review of the Income Tax, Schedule D, which he took to be derived from labour and not from material capital, together with a calculated amount for the management of the total material capital, or a total of $12,000,000,000 l$. By 
capitalising the salaries of officials coming under Schedule $\mathrm{E}$, he obtained a sum of $1,000,000,000 l$, and to these figures he added a further sum of 10,000,000,0ool. as an estimate of the value of what he termed "domesticated humanity." He thus obtained a grand total of $47,000,000,000 l$., or an average capital value per head of the population of $\mathrm{x}, 25 \mathrm{ol}$.

The value for domesticated humanity was an estimate of the cost of production made on the assumption that every person costs as much to produce as the value of the house he lives in, and Professor Nicholson stated that "this item is obtained by con" sidering the people as valuable "things in themselves' and not " merely as wage-earners." Professor Nicholson's method was a combination of the "yield" and "cost" methods. While we may agree that the whole of the cost is required to produce the persons who are valuable as "things in themselves" and not merely as wage-earners, at the same time and for the same expense wage-earners are produced, and, therefore, there appears to be a certain duplication of values when such cost of production is added to the capitalised value of the wages earned by the persons whose cost of production we have estimated.

In December, 1910, and May, 1911, two papers were contributed to the Revue Economique Internationale by the French actuary, M. Barriol, on "The Social Value of an Individual." The results of M. Barriol's calculations have been used by M. Yves Guyot in his article on "The Waste of the War" in the Nineteenth Century for December, 1914, and by Mr. Crammond in his paper already mentioned. As both of these writers appear to have used the average values arrived at by $\mathbf{M}$. Barriol without apparently any regard to the special circumstances of the cases to which they have been applied, it may be well for us to examine briefly the methods set forth in M. Barriol's papers.

M. Barriol adopted the "yield" method, and defined the "social value" of an individual as that which he will restore to the community from his earnings. He then assumed certain wages scales, and on similar lines to those adopted in formulating pension fund tables based on salary scales, allowing for a rate of mortality and a 3 per cent. rate of interest, arrived at "social "values" for each year of age. In his first paper M. Barriol gave illustrative tables for two classes of the French population.

In his second paper calculations of average social values were made for various countries. The average values for quinquennial age groups were taken, and each value was multiplied by the population corresponding to that group. By summing the values 
obtained and dividing by the total population, a weighted average social value was obtained applicable to the whole male population, taking one age with another, from birth to the extreme limits of old age. M. Barriol then applied a coefficient of increase or reduction (as the case required) to allow for the difference between the standard of wages in France and other countries. Then recognising that the value obtained was too high, as it assumed that the females (approximately half of the population) earned the full wages scale based upon average male earnings, he rectified this by multiplying by a coefficient which made the result represent an average not only for all ages, but also applying to the whole population, male and female. The average value thus obtained for England was 20,700 francs, say 828l., which is the figure quoted by M. Yves Guyot and Mr. Crammond.

It is surely incorrect, however, to take a figure which has been reduced to make it specially applicable as an average to the values of children, women and aged persons and apply it to the casualties of male combatants mainly of " military age," particularly when the original unadjusted values are obtainable in M. Barriol's tables. The values for ages, say, 20 to 40 , were the maximum values of the table, and before such values were reduced to include the female population the capital value for an Englishman of military age was over $x, 700 l$.

Mr. Crammond in support of the figure of 8287 . quotes the compensation given under the Workmen's Compensation Acts and from relief funds for the loss of a breadwinner; but is this a true test to apply? As already stated, in the discussion of Dr. Farr's methods, the economic loss sustained by a family is the loss of the man's income, less his own cost of maintenance, and not the full loss of income.

It is because there are such differences that we find it difficult to give any very definite answer to our second question: On what basis should human capital be valued? Different methods are applicable according to the object we have in view. It depends whether we wish to apply our results to the questions of emigration and depopulation, compensation to dependants, the problems of capital (in its more usual sense) and labour, estimates of human progress, or to the losses caused by devastating wars.

In deciding between the "cost" and "yield" methods, there is little choice on the score of accuracy of data, as actual figures for cost are as difficult to obtain as correct estimates of average future earnings. Combinations of the "cost" and "yield" methods are dangerous, owing to the possibility of duplication 
of values. Our own preference is in favour of the "yield" method as lending itself to more scientific treatment and because it only attempts to value material benefits, while the "cost" method may include expenditure on the development of the individual apart from the increase in his earning power, which development we have purposely placed outside the scope of our notes.

If the "yield" method be adopted, we have to decide whether we are to capitalise gross or net income, and this is, again, largely a question of the use we wish to make of our results. For the purpose of estimating war losses, the capitalisation of a man's total income is probably preferable, as the future loss of income due to the destruction of human capital is then more comparable with the total national income, which is usually expressed in the form of a sum of the individual gross incomes.

It is also important to notice that the chief factors determining human capital values are age, station in life (as affecting cost of maintenance and rates of remuneration), sex, mortality and interest. It is only when all these factors are considered that the resulting values can be safely applied to a case such as the present war, in which the loss of life is greater among the officers than among the men, of which the losses (at any rate of the combatants) are all of one sex, and in which the ages of the men killed and wounded are not average ages of the whole population, but fall within certain comparatively definite limits. 